\title{
A judicialização do processo político e a politização do poder judiciário: uma análise da intervenção do supremo tribunal federal no processo político partidário*
}

Ana Paula de Almeida Lopes ${ }^{1}$

\section{Resumo}

O presente estudo tem por objetivo analisar o controle de constitucionalidade do Supremo Tribunal Federal em relação ao processo político partidário, partindo-se da análise dos julgamentos da medida cautelar na ADIn $\mathrm{n}^{\circ} 1.354$, ajuizada pelo Partido Social Cristão - PSC, e da ação principal, ADIn n 1.351, ajuizada pelo Partido Democrático Trabalhista - PDT e pelo Partido Comunista do Brasil - PC do B, com o objetivo de impedir a vigência da cláusula de barreira, prevista no artigo 13 da Lei $n^{\circ}$ 9.096/95 - Lei dos Partidos Políticos. Ambos os julgamentos tiveram votações unânimes, apesar das divergentes decisões. Com efeito, no julgamento do pedido liminar, na ADIn no 1.354, julgada em 1996, indeferiu-se a declaração de inconstitucionalidade da cláusula de barreira. No entanto, em dezembro de 2006, no julgamento da ADIn n 1.351 , foi julgado o seu deferimento. A partir disso, para avaliar as implicações jurídicas e políticas dessas decisões para a democracia brasileira, são investigados dois efeitos: a judicialização da política e a politização da justiça. O primeiro, basicamente, caracteriza-se pela intervenção do Supremo na arena política, e o segundo pela influência de fatores políticos externos que influenciaram a decisão do Supremo nos dois julgamentos. Assim, por meio desse panorama, busca-se ponderar o impacto político do STF na definição das regras do regime democrático não apenas como "guardião da Constituição Federal”, o que implica certa neutralidade nas suas decisões, mas também pela influência de questões de conveniência política decorrentes da composição do governo federal e do Congresso Nacional. Por fim,

\footnotetext{
Artigo recebido em: 30/09/2010.

Artigo aprovado em: 09/11/2010.

1 Doutoranda em Ciência Política na Universidade Federal do Rio Grande do Sul - UFRGS, Mestre em Direito pelo Programa de Pós-Graduação em Direito na Universidade do Vale do Rio dos Sinos - Unisinos, com ênfase em Direito Constitucional e Ciência Política. Atualmente é professora do curso de Direito na Escola Superior de Administração Direito e Economia - ESADE.
} 
conclui-se que ambas as decisões do Supremo, em períodos distintos, 1996 e 2006, foram instrumentais, ou seja, de acordo com as necessidades políticas do governo para manter e /ou aumentar a sua base governista em situações específicas.

Palavras-chave: Controle de constitucionalidade. Judicialização da política. Politização da justiça. Partidos políticos. Cláusula de barreira.

\section{Considerações iniciais}

O subdesenvolvimento partidário tem sido apontado como uma causa de notoriedade do Brasil frente aos demais países da América Latina. Fragilidade, efemeridade e fracas raízes na sociedade ao mesmo tempo em que ilustram as principais características dos atuais partidos políticos brasileiros, foram também peculiaridades dos tantos sistemas partidários quantos foram os regimes políticos que se sucederam no Brasil desde o Império.

Nesse sentido, com a aparência de um mecanismo de fortalecimento do atual sistema partidário, a cláusula de barreira foi introduzida no teor da Lei $n^{\circ}$ 9.096/95, estabelecendo que só teriam representação na Câmara dos Deputados os partidos políticos que obtivessem 5\% dos votos válidos, excluídos os brancos e nulos, apurados em nível nacional, devendo ser distribuídos em um terço dos Estados e atingir o percentual de $2 \%$ em cada um deles. A aplicação dessa cláusula, à época da promulgação da referida Lei, a princípio reduziria em torno de $50 \%$ o número de partidos representados na Câmara dos Deputados. Apesar disso, não afetaria as alianças de governo, pois os partidos que alcançam a barreira de 5\% são responsáveis por, pelo menos, $80 \%$ dos votos nacionais. ${ }^{2}$

Contudo, a discussão do tema é levada pelos partidos de oposição ${ }^{3}$ para a arena judicial via Ação Direta de Inconstitucionalidade a fim de impedir a vigência

2 MACHADO, Sérgio. Reforma político-partidária. Brasília: Senado Federal, 1998. Relatório Final.

3 A saber, o PSC (Partido Social Cristão), PC do B (Partido Comunista do Brasil), PDT (Partido Democrático Trabalhista) entre outros. 
da cláusula de barreira. Em 7 de fevereiro de 1996, é julgada a medida cautelar, ADIn n ${ }^{\circ}$ 1.354-8, declarando a constitucionalidade da cláusula de barreira, por unanimidade, sob a alegação de que o referido artigo 13 não ofende os princípios consagrados na Constituição Federal. Ao contrário, afirmou-se que os dispositivos impugnados "são mecanismos de proteção para a própria convivência partidária."

Por outro lado, dez anos depois, no julgamento da ação principal, ADIn $\mathrm{n}^{\circ}$. 1351-3, em 7 de dezembro de 2006, o Supremo declara a inconstitucionalidade da cláusula de barreira também por unanimidade. O fundamento dessa decisão embasou-se no argumento de que o referido dispositivo "afasta o funcionamento parlamentar e reduz substancialmente o tempo de propaganda partidária gratuita e a participação no rateio do Fundo Partidário."

De ambos os julgamentos podem ser extraídos dois efeitos contemporâneos na interação entre política e justiça: a judicialização da política e a politização da justiça. O primeiro caracteriza-se pela notável expansão do poder judicial a partir do fim da II Guerra Mundial na Europa Ocidental, cuja influência no Brasil é identificada, principalmente, por autores como Castro e Werneck Vianna. Já o segundo refere-se aos fatores políticos que influenciaram a forma como o STF decidiu e, por evidência, a causa de seus divergentes julgamentos, na ADIn no 1.354 e $1.351 .^{4}$

Assim, para alcançar o desenvolvimento do tema recém-delineado, num primeiro momento, será avaliada a decisão da ADIn n ${ }^{\circ} 1.351$ sob o prisma metodológico da judicialização do processo político, em razão de que a intervenção do Supremo na arena política só se deu a partir do julgamento do mérito da ação principal, quando declarou a inconstitucionalidade da cláusula de barreira. Após, serão examinados, sob o enfoque da politização da justiça, os fatores políticos que influenciaram a decisão do Supremo no julgamento do pedido liminar e da ação principal, ADIns no 1.354 e 1.351, respectivamente. Por meio desse panorama,

4 Utilizou-se a concepção de politização da justiça aplicada por Marcelo Paiva Santos na análise da interferência e condicionamento do direito por parte do regime militar, instaurado a partir de 1964 até a promulgação da Constituição de 1988. SANTOS, Marcelo Paiva dos. A história não contada do Supremo Tribunal Federal. Porto Alegre: S. A. Fabris, 2009. 
busca-se avaliar o impacto político do STF na definição das regras do regime democrático não apenas como "guardião da Constituição Federal", o que implica em uma certa neutralidade nas suas decisões, mas também sob a influência de questões de conveniência política decorrentes da composição do governo federal e do Congresso Nacional.

\section{0 caso das ADINS no 1.354-8 e 1.351-3}

O julgamento da ADIn no $1.354-8,{ }^{5}$ relatada pelo Ministro Maurício Corrêa, em decisão unânime, julgou o indeferimento do pedido liminar, sob o argumento de que o funcionamento parlamentar deve estar subordinado ao que regulamentar a lei, já que os limites estão impostos no art. 17 da Constituição Federal, e que não há afronta ao princípio da igualdade pelo artigo 13 da Lei dos Partidos Políticos, conforme a ementa in verbis:

MEDIDA CAUTELAR EM AÇÃO DIRETA DE INCONSTITUCIONALIDADE. SUSPEIÇÃO DE MINISTRO DA CORTE: DESCABIMENTO. PARTIDOS POLÍTICOS. LEI No 9.096, DE 19 DE SETEMBRO DE 1995. ARGUIÇÃO DE INCONSTITUCIONALIDADE DO ART. 13 E DAS EXPRESSÕES A ELE REFERIDAS NO INCISO II DO ART. 41, NO CAPUT DOS ARTS. 48 E 49 E AINDA NO INCISO II DO ART. 57, TODOS DA LEI No 9.096/95.

\section{[...]}

2. O artigo 13 da Lei $\mathrm{n}^{\circ}$ 9.096, de 19 de setembro de 1995, que exclui do funcionamento parlamentar o partido político que em cada eleição para a Câmara dos Deputados, não obtenha o apoio de no mínimo cinco por cento dos votos

\footnotetext{
5 Ao tempo do julgamento da ADIn no 1.354-8, em 1996, a composição do STF, bem como do Plenário era a seguinte, considerando-se a indicação presidencial e o ano da posse: Ministro Presidente José Paulo Sepúlveda Pertence (Presidente José Sarney, 1989), José Carlos Moreira Alves (Presidente Ernesto Geisel, 1975), José Néri da Silveira (Presidente João Figueiredo, 1981), Luiz Octavio Pires e Albuquerque Gallotti (Presidente João Figueiredo, 1984), Sydney Sanches (Presidente João Figueiredo, 1985), José Celso de Mello (Presidente José Sarney, 1989), Carlos Mário da Silva Velloso (Presidente Fernando Collor, 1990), Marco Aurélio Mendes de Farias Mello (Presidente Fernando Collor, 1990), Ilmar Nascimento Galvão (Presidente Fernando Collor, 1991), João Francisco Rezek (Presidente Fernando Collor, 1992), Maurício Corrêa (Presidente Fernando Henrique, 1994).
} 
válidos distribuídos em, pelo menos, um terço dos Estados, com um mínimo de dois por cento do total de cada um deles, não ofende o princípio consagrado no artigo 17, seus incisos e parágrafos, da Constituição Federal. (grifado no original)

3. Os parâmetros traçados pelos dispositivos impugnados constituem-se em mecanismos de proteção para a própria convivência partidária, não podendo a abstração da igualdade chegar ao ponto do estabelecimento de verdadeira balbúrdia na realização democrática do processo eleitoral. (grifado no original) [...]

6. A norma contida no artigo 13 da Lei no 9.096/95 não é atentatória ao princípio da igualdade; qualquer partido, grande ou pequeno, desde que habilitado perante a Justiça Eleitoral, pode participar da disputa eleitoral, em igualdade de condições, ressalvados o rateio dos recursos do fundo partidário e a utilização do horário gratuito de rádio e televisão - o chamado "direito de antena" -. Ressalvas essas que o comando constitucional inscrito no artigo $17, \S 3^{\circ}$, também reserva à legislação ordinária a sua regulamentação.

7. Pedido de medida liminar indeferido. ${ }^{6}$

Pode-se observar que as insurgências contra a cláusula de barreira foram afastadas em virtude do julgamento da liminar da ADIn $n^{\circ} 1.354-8$ que, por unanimidade, reconheceu a sua constitucionalidade. Fundamenta que o artigo 13 não viola o princípio da igualdade, pois os partidos concorrem em igualdade de condições, ressalvada a participação no fundo partidário e o "direito de antena" para aqueles partidos que não preencherem as condições do dispositivo.

Por outro lado, o julgamento da ADIn $n^{\circ} 1.351-3^{7}$ conseguiu modificar o “quadro de desigualdade” provocado pela inserção da cláusula de barreira. Propos-

6 BRASIL. Supremo Tribunal Federal. Ação Direta de Inconstitucionalidade. Partido Social Cristão e Congresso Nacional. ADIn $n^{\circ}$ 1.354-8. Tribunal Pleno. Relator: Ministro: Maurício Corrêa. Brasília, 7 de fevereiro de 1996.

7 A composição do Plenário no julgamento da ADIn no. 1.351-3, em dezembro de 2006, considerando a indicação presidencial e o ano da posse, era a seguinte: Presidente Ministra Ellen Gracie (Presidente Fernando Henrique Cardoso, 2000), Sepúlveda Pertence (Presidente José Sarney, 1989), Celso de Mello (Presidente José Sarney, 1989), Marco Aurélio (Presidente Fernando Collor, 1990), Gilmar Mendes (Presidente Fernando Henrique Cardoso, 2002), Cezar Peluso (Presidente Lula, 2003), Carlos Britto (Presidente Lula, 2003), Eros Grau (Presidente Lula, 2004), Ricardo Lewandowski (Presidente Lula, 2006), Carmem Lúcia (Presidente Lula 2006). 
ta pelo Partido Comunista do Brasil - PC do B, Partido Democrático Trabalhista - PDT entre outros partidos, com a finalidade de declarar a inconstitucionalidade do art. 13 da Lei no 9.096/95, foi julgada em 7 de dezembro de 2006, ou seja, antes da legislatura que iniciaria em 2007. Conforme a decisão unânime do Supremo Tribunal Federal, cujo Relator foi o Ministro Marco Aurélio, “a gradação de votos obtidos por partido político, afasta o funcionamento parlamentar e reduz, substancialmente, o tempo de propaganda partidária gratuita e a participação no rateio do Fundo Partidário." 8

Notavelmente, os efeitos decorrentes da aplicabilidade da cláusula de barreira ensejariam a desigualdade em relação à distribuição do fundo partidário e do tempo disponível para propagandas partidárias, o que favoreceria, de certa forma, o domínio de uma "elite" partidária nas bancadas do Congresso Nacional em detrimento dos partidos menores. Estes últimos, tendo em vista a falta de recursos e propaganda, ficariam "condenados ao esquecimento e à inanição", para o que chamaram a atenção o Ministro Relator Marco Aurélio juntamente com os Ministros Sepúlveda Pertence e Gilmar Mendes no referido acórdão.

No entanto, sabendo-se que, a posteriori, a declaração de inconstitucionalidade do mesmo dispositivo pela ADIn n ${ }^{\circ}$ 1.351-3 foi realizada por meio da interpretação da mesma Lei e da mesma Constituição, apesar do curto interregno, que razão há para declarar a defesa da igualdade entre a maioria e a minoria no sistema representativo brasileiro sob a égide da Constituição Federal de 1988? Afinal, os argumentos utilizados para a declaração de inconstitucionalidade da cláusula de barreira, que antes fora declarada constitucional, têm conotação constitucional ou política?

\footnotetext{
8 BRASIL. Supremo Tribunal Federal. Ação direta de inconstitucionalidade. Partido Comunista do Brasil e Congresso Nacional. ADIn $n^{\circ}$ 1.351-3. Tribunal Pleno. Relator: Ministro Marco Aurélio. Brasília, 30 de março de 2007. Disponível em: <http://www.stf.jus.br/ imprensa/pdf/votoerosadi1351.pdf>. Acesso em: 9 jul. 2008. p. 19.

9 Termo utilizado por Scott Mainwaring quando se refere aos partidos que buscam conquistar um maior número de votos (catch-all parties), atraindo os eleitores situados nos mais diversos espectros de preferências políticas. São, na verdade, partidos "descentralizados, indisciplinados e individualistas." MAINWARING, Scott P. Sistemas partidários em novas democracias: o caso do Brasil. Tradução Vera Pereira. Porto Alegre: Mercado Aberto, 2001. p. 34.
} 
Assim, antes de adentrarmos na discussão sobre o processo de judicialização do processo político no Brasil, e avaliarmos a intervenção de fatores externos ou políticos que afetaram a imparcialidade do Supremo, faz-se necessário tratarmos do papel político do STF na democracia brasileira.

\section{0 papel político do Supremo Tribunal Federal}

A atribuição do Supremo Tribunal Federal de guardião dos direitos fundamentais foi introduzida na cultura jurídico-política brasileira com a divulgação da obra The American Commonwealth de James Bryce, por Rui Barbosa. Contudo, Álvaro R. de Souza Cruz destaca que, ao contrário dos Estados Unidos em que o controle de constitucionalidade nasce como fruto da interpretação judiciária ${ }^{10}$, no Brasil, surge pela via do direito positivo, mediante sua inclusão formal no texto constitucional, da mesma maneira com que foram introduzidos os direitos fundamentais na Constituição de $1988 .{ }^{11}$

Assim, o caráter político do Supremo Tribunal Federal deve-se à sua prerrogativa de declarar o sentido e o alcance das regras jurídicas, assegurada pela Constituição Federal de 1988. Apesar disso, a competência do STF no novo texto constitucional foi tema de intenso debate. Com efeito, nos meses que antecederam à Constituinte de 1987, era considerável o número de juristas que protestavam, por meio da imprensa, a necessidade de conferir ao Supremo Tribunal Federal

${ }^{10} \mathrm{O}$ controle de constitucionalidade nos Estados Unidos foi iniciado com o caso Marbury versus Madison, de 1802, em que o Chief Justice John Marshall fixou aquilo que foi chamado precisamente de supremacia da Constituição, bem como institucionalizou o dever-poder dos juízes de negarem a aplicação de leis que entendessem contrárias à Constituição. Por outro lado, a Suprema Corte Norte-Americana adota o critério de controle difuso, ou seja, só pode se pronunciar sobre um caso ou controvérsia real, de modo que não existe controle de normas abstrato. Apesar da decisão não ser tomada em relação a um caso concreto, o efeito não é inter partes, isso porque, no sistema common law, os precedentes têm força vinculante (stare decisis). CAPPELLETTI, Mauro. O controle de constitucionalidade das leis no direito comparado. Porto Alegre: S. A. Fabris, 1984.

${ }^{11}$ CRUZ, Álvaro Ricardo de Souza. Breve histórico do Supremo Tribunal Federal e do controle de constitucionalidade brasileiro. SAMPAIO, José Adércio Leite. Crise e desafios da Constituição. Belo Horizonte: Del Rey, 2003. 
atribuições jurídico-políticas de uma Corte Constitucional. ${ }^{12}$ Em declaração ao jornal Folha de São Paulo, em 9/10/1986, Miguel Reale Junior considerou que "as atribuições do STF deveriam ser predominantemente constitucionais, como nos Estados Unidos da América."13 Foi no âmbito da Comissão da Organização de Poderes e Sistema de Governo, na Subcomissão do Poder Judiciário e do Ministério Público, que se iniciou o debate sobre o papel e a competência do STF na nova Constituição brasileira.

O primeiro relatório, seguindo as orientações dos Anteprojetos de José Afonso e da Comissão Arinos, instituía a Corte Constitucional, que seria dedicada às questões constitucionais, e o Superior Tribunal de Justiça, o qual deveria incorporar as demais atribuições do STF. A reação contrária da maioria conservadora no âmbito da Subcomissão foi imediata. As principais reclamações giravam em torno da "tradição positivista do nosso direito" e do fim da "garantia sagrada da vitaliciedade no direito brasileiro." Assim, a alternativa encontrada foi manter o Supremo Tribunal Federal, mas com atribuições de Corte Constitucional, transferindo para o novo Superior Tribunal de Justiça algumas das suas antigas atribuições. ${ }^{14}$

Observe-se que a pressão do Judiciário e a ação coordenada dos ministros foram sentidas no âmbito da Assembléia Constituinte. Com efeito, o Anteprojeto da Comissão da Organização dos Poderes e Sistema de Governo dispunha que o STF seria integrado por 16 ministros, sendo 5 indicados pelo Presidente da República, 6 indicados pela Câmara dos Deputados e 5 indicados pelo Presidente da República dentre integrantes de listas tríplices, organizadas para cada vaga pelo STF. No entanto, o segundo substitutivo do Relator demonstrou o resultado dessa

${ }^{12}$ CITTADINO, Gisele. Pluralismo, direito e justiça distributiva: elementos da filosofia constitucional contemporânea. 3. ed. Rio de Janeiro: Lumen Júris, 2004.

${ }^{13}$ REALE JUNIOR, Miguel apud CITTADINO, Gisele. Pluralismo, direito e justiça distributiva: elementos da filosofia constitucional contemporânea. 3. ed. Rio de Janeiro: Lumen Júris, 2004. p. 60.

${ }^{14}$ CITTADINO, Pluralismo, direito e justiça distributiva: elementos da filosofia constitucional contemporânea. 3. ed. Rio de Janeiro: Lumen Júris, 2004. p. 61. Vide também, nesse sentido, a entrevista de Plínio de Arruda de Sampaio para o Memorial do Ministério Público. BISCHOFF, Álvaro Walmrath; AXT, Gunter; SEELIG, Ricardo Vaz. Histórias de vida do Ministério Público do Rio Grande do Sul: a Constituinte de 1988. Porto Alegre: Procuradoria-Geral de Justiça, Memorial do Ministério Público, 2006. p. 259-292. 
pressão: o STF continuaria a ser integrado por onze ministros, todos indicados pelo Presidente da República, ouvido o Senado Federal.

Apesar do STF não ter sido transformado em Corte Constitucional, foi-lhe atribuída a função de "guardião da Constituição" (art. 102, CF) e parte de suas antigas atribuições foram transferidas para o novo Superior Tribunal de Justiça. De tal modo, a Constituição Federal de 1988 manteve a fórmula de controle misto de constitucionalidade, ou seja, difuso na figura do Juiz Singular, e concentrado na figura do Supremo Tribunal Federal, bem como a remessa ao Senado no julgamento de Recurso Extraordinário.

Importante ressaltar a diferença daquilo que diz respeito ao caráter político do STF e o que indica o fenômeno de politização das decisões proferidas por essa Corte. Com efeito, o caráter político do Supremo diz respeito ao exercício de uma função estatal destinada à guarda da Constituição por meio do controle misto de constitucionalidade das leis, o que pressupõe certa neutralidade valorativa na solução desses conflitos, uma vez que as decisões devem ser fundamentadas estritamente no conteúdo do texto constitucional e seus princípios. Por outro lado, a politização da Justiça implica a contaminação política da suposta neutralização do Judiciário e, nesse caso, do Supremo, por se tratar de órgão composto por membros indicados pelos chefes do Poder Executivo.

Por essa razão, procurar-se-á demonstrar a partir da análise das decisões proferidas no julgamento do artigo 13 da Lei no 9.096/95 que a Política pode definir os rumos do Direito, mesmo fora de um regime de exceção, ainda que se afirme que o poder político não seja fundamento das decisões do Supremo Tribunal Federal.

\subsection{A organização e composição do Supremo Tribunal Federal}

Conforme analisado no item anterior, a partir da Constituição Federal de 1988, o Supremo Tribunal Federal evoluiu para um tribunal no qual coexistem características próprias do sistema americano e europeu de jurisdição constitucional. 
Não obstante o hibridismo de sua jurisdição, a organização do STF permanece fiel ao modelo norte-americano, ou seja, juízes vitalícios que são indicados livremente pelo Presidente da República e nomeados após a confirmação pelo Senado Federal, sendo o órgão de cúpula do Poder Judiciário. ${ }^{15}$

Desse modo, o sistema adotado no Brasil convoca a participação integrada dos Poderes Executivos e Legislativos, o que garantiria o caráter democrático ao processo, uma vez que o Presidente da República e Senadores são eleitos diretamente pelo povo. Para Tavares Filho (2006), a motivação para a livre escolha dos Ministros do STF reside na conviç̧ão de que o papel dos Ministros não tem caráter apenas jurisdicional, mas também político na estrutura dos Poderes. Logo, em função de seu peculiar papel político, o Supremo é colocado fora da carreira da magistratura, não sendo acessível em um plano de promoções.

A liberdade dada ao Presidente da República e ao Senado Federal permitiria a escolha de candidatos que possuíssem não apenas o saber jurídico e a reputação ilibada que a Constituição requer expressamente, mas também a habilidade de lidar com as implicações políticas das questões trazidas ao julgamento do Tribunal, fundados em sua experiência jurídica e em sua vivência como cidadão e indivíduo. Ainda, a vitaliciedade dos Ministros do STF decorre, principalmente, da garantia da independência desse órgão, eis que os Ministros estariam livres de prestar contas àqueles que os nomearam, ou seguir-lhes as orientações.

No entanto, apesar de sua longa tradição, esse sistema não está livre de abusos por diversos fatores. Primeiramente, o cumprimento dos requisitos constitucionais de notável saber jurídico e reputação ilibada é uma das principais dificuldades enfrentadas na história constitucional brasileira. ${ }^{16}$ Em segundo lugar, a inércia do Senado quanto à aprovação dos nomes torna protocolar o exame da indicação,

\footnotetext{
${ }^{15}$ Consoante a Constituição brasileira atual, podem ser nomeados Ministros do STF os cidadãos que preenchem as seguintes condições (art.101): ter mais de trinta e cinco anos e menos de sessenta e cinco anos de idade, notável saber jurídico e reputação ilibada.

${ }^{16}$ A Constituição de 1891 não era específica quanto ao saber jurídico, tanto é que o Marechal Floriano Peixoto indicou, em 1892, o médico Candido Barata Ribeiro e dois generais para o cargo de Ministro do STF.
} 
uma vez que aprova de modo automático a designação que lhe é submetida pelo Presidente. Em terceiro lugar, a influência dos laços de amizade e compromisso entre os indicados e o Presidente da República ou a sua base parlamentar não é estranha à nossa atual prática constitucional. Por fim, os magistrados tanto do Supremo Tribunal Federal quanto dos demais Tribunais Superiores podem reingressar na vida política após a sua aposentadoria como Ministros.

Com efeito, o Presidente Luiz Inácio Lula da Silva já nomeou oito ministros para o Supremo Tribunal Federal: três advogados (Carlos Ayres Britto, Eros Grau e Carmem Lúcia); um juiz egresso da magistratura estadual (César Peluso); um desembargador estadual (Ricardo Lewandowski); um membro do Ministério Público Federal (Joaquim Barbosa); um Ministro aposentado do STJ (Menezes Direito), bem como o seu sucessor, o Ministro José Antonio Dias Toffoli. Segundo o autor, essa peculiaridade do governo Lula deu ensejo a acusações de "aparelhamento" e "partidarização" do Tribunal, eis que suas escolhas podem redefinir a orientação ideológica do Supremo.

Por outro lado, tomando-se como parâmetro o modelo europeu de Tribunal Constitucional, que se disseminou pela Europa a partir de 1920, o controle de constitucionalidade é entregue exclusivamente a um tribunal situado fora da estrutura judiciária. Comparativamente, na França, a partir da Constituição de 1958, existe um Conseil Constitutionnel composto pelos ex-Presidentes da República e por outros nove membros. Destes, três são nomeados pelo Presidente da República, três pelo Presidente da Assemblée Nationale, e três pelo Presidente do Senát. Assim, é reconhecida por numerosos estudiosos franceses a natureza não jurisdicional ou política da função exercida pelo Conseil Constitutionnel, a qual se revela na escolha dos membros que dela fazem parte, especialmente pelo seu caráter necessário no controle das leis orgânicas, que se desenvolve sem um recurso ou impugnação de parte. ${ }^{17}$

${ }^{17}$ CAPPELLETTI, Mauro. O controle de constitucionalidade das leis no direito comparado. Porto Alegre: S. A. Fabris, 1984. 
Na Alemanha, por sua vez, o sistema de controle de normas está concentrado no Tribunal Constitucional Federal (BundesverfassungsgerichtI), cuja lei disciplinadora acabou por tornar usual a denominação "controle abstrato de normas". Nesse sentido, o Tribunal é constituído por dois Senados, compostos por oito juízes cada, eleitos pelo Parlamento Federal (Bundestag) e pelo Conselho Federal (Bundesrat). Os Senados encontram-se no mesmo plano hierárquico, dispondo de Câmaras compostas por três juízes para a realização do exame prévio sobre o cabimento de recursos constitucionais.

Assim, três membros de cada Senado são escolhidos dentre os juízes que integram outros Tribunais Federais. Os juízes eleitos pelo Conselho Federal (Bundesrat) são escolhidos mediante eleição direta, na qual os votos de cada Estado são dados de forma unitária; enquanto que para os juízes escolhidos pelo Parlamento Federal, deve-se fazer uma eleição indireta por colégio composto de doze parlamentares e formado segundo as regras da eleição proporcional. Os integrantes desse colégio são eleitos para uma legislatura, não podendo ser destituídos, sendo que as decisões devem ser tomadas por maioria qualificada de $2 / 3$, o que torna imperioso um consenso dos dois grandes partidos. Para Mendes, torna-se "inevitável, pois, que a composição do Tribunal reflita a representatividade parlamentar dos partidos políticos" ${ }^{18}$ Ademais, a nomeação do juiz eleito é da competência do Presidente da Republica, cujo ato tem significado meramente declaratório.

Com base nisso, uma das alternativas de mudança na composição do STF que possa oferecer uma participação democrática no processo se sua composição é transformá-lo em corte constitucional pura e, portanto, fora do sistema judiciário e com competência exclusiva para questões constitucionais. ${ }^{19}$ Contudo esta seria a solução mais radical para o nosso sistema atual, sendo que outra seria forçar o Senado a ter uma participação mais ativa na escolha dos Ministros do STF, por meio

\footnotetext{
${ }^{18}$ MENDES, Gilmar Ferreira. Jurisdição Constitucional: o controle abstrato de normas no Brasil e na Alemanha. 3. ed. São Paulo: Saraiva, 1999. p. 5.

${ }^{19}$ Cappelletti reconhece que "até um judiciário inicialmente dedicado à proteção da liberdade dos cidadãos, pode terminar, malgrado seu, por se transformar em instrumento de tirania, se privado por longo tempo de legitimação democrática”. CAPPELLETTI, Mauro. Juízes legisladores? Porto Alegre: S. A. Fabris, 1999. p. 94.
} 
da fixação de quorum mais elevado para a confirmação das indicações feitas pelo Presidente da República, em sessão aberta, sendo vedado o voto secreto. Tavares Filho ressalta que o risco dessa mudança seria a possibilidade de paralisar o processo e nomeação até que fosse atingido um consenso.

Apresentadas algumas das principais particularidades do Supremo Tribunal Federal no que diz respeito ao controle de constitucionalidade das leis, passaremos à análise das decisões proferidas nas ADIns no 1.354-8 e 1.351-3 sob os prismas de dois eventos: a judicialização da política e a politização da justiça.

\section{A judicialização da política e o constitucionalismo democrático no Brasil}

A notável expansão do poder judicial em várias democracias ocidentais, a partir da segunda metade do século XX, por meio do controle normativo sobre os demais poderes, propiciou uma nova arquitetura institucional, que viabilizou a participação do Poder Judiciário nos processos decisórios. ${ }^{20}$ Por outro lado, a ampliação do controle normativo do Judiciário tem sido alvo de muitas críticas e discussões, principalmente, pela polêmica que gera em torno dos princípios de separação de poderes e da neutralidade política do Poder Judiciário, o que implicaria a desvinculação do espaço público das clássicas instituições político-representativas. ${ }^{21}$

Esse evento ficou conhecido como "judicialização da política", apesar da fluidez de seu aspecto conceitual, tendo em vista a multiplicação dos usos e sentidos dessa expressão. Assim, compartilhando da concepção de Oliveira, esse fenômeno só ocorreria ao julgamento do mérito da ação, isto é, quando o Poder

${ }^{20}$ CARVALHO, Ernani Rodrigues. Em busca da judicialização da política no Brasil: apontamentos para uma nova abordagem. Revista de Sociologia Política, Curitiba, n. 23, p. 115-126, nov. 2004.

${ }^{21}$ CITTADINO, Gisele. Judicialização da política, constitucionalismo democrático e separação de poderes. In: WERNECK VIANNA, Luiz (Org.). A democracia e os três poderes no Brasil. Belo Horizonte: UFMG; Rio de Janeiro: IUPERJ/FAPERJ, 2002. 
Judiciário interfere na política, o que concretamente ocorreu no julgamento da ADIn $n^{\circ} .1 .351 .^{22}$

Nesse sentido, Carvalho sintetiza as duas formas de abordagem da judicialização da política da seguinte maneira: a) normativa, a qual trata da supremacia da Constituição sobre as decisões parlamentares majoritárias. Esse debate avalia os dilemas da evolução do constitucionalismo sobre a democracia. Entre os que são a favor da judicialização, estão Dworkin e Cappelletti, e os que são a favor desde que expressos certos limites estão, Habermas e Ely Garapon; b) analítica, que se preocupa com a análise do ambiente político e institucional, a fim de definir, medir e avaliar o processo de judicialização da política. ${ }^{23}$

Em razão desse método de abordagem tratar da intervenção do Poder Judiciário na regulação da disputa política, que neste estudo é debatida sob o aspecto da judicialização do processo político, passaremos à abordagem analítica do processo de judicialização, a fim de analisar se no Brasil existem as condições políticas para a realização desse fenômeno, principalmente, no que toca à regulação da disputa político-partidária.

\subsection{Abordagem analítica do processo de judicialização da política no Brasil}

Alguns fatores propiciaram o surgimento desse evento que se tornou tão característico das democracias contemporâneas e que pode ser entendido, segundo Castro, como uma expansão do escopo das questões sobre as quais os tribunais judiciais devem formar juízos jurisprudenciais. Dentre os fatores que favoreceram o seu aparecimento estão: a queda do comunismo no Leste europeu e o fim da União Soviética; o colapso do socialismo real e o crescimento do capitalismo

${ }^{22}$ OLIVEIRA, Vanessa Elias de. Judiciário e privatizações no Brasil: existe uma judicialização da política? DADOS - Revista de Ciências Sociais, Rio de Janeiro, v. 48, n. 3, p. 559-587, 2005. Disponível em: <http://www.scielo.br/pdf/dados/v48n3/a04v48n3.pdf>. Acesso em: 13 jul. 2008.

${ }^{23}$ CARVALHO, Ernani Rodrigues. Em busca da judicialização da política no Brasil: apontamentos para uma nova abordagem. Revista de Sociologia Política, Curitiba, n. 23, p. 115-126, nov. 2004. 
e suas instituições; a hegemonia dos Estados Unidos; a evolução da jurisprudência constitucional; as guerras mundiais; os direitos humanos; e o neoliberalismo entre outros. $^{24}$

Além disso, seguindo o fio condutor de Tate, Carvalho avalia que o surgimento da judicialização implica a existência de certas condições políticas, a saber: democracia, separação de poderes, direitos políticos, uso dos tribunais por grupos de interesse, o uso dos tribunais pela oposição e a inefetividade das instituições majoritárias. Desse modo, a democracia é condição necessária, mas não suficiente, uma vez que um governo autoritário é incompatível com a expansão judicial, conforme pode ser analisado na própria história do Supremo Tribunal Federal. ${ }^{25}$ A separação dos poderes propicia uma limitação e controle maiores dos atos do Poder Executivo pelo Judiciário. A constitucionalização dos direitos políticos pode significar um ponto forte contra a "supremacia da maioria", porém não é condição suficiente. Ainda, o uso dos tribunais pelos grupos de interesse deve-se ao fato de que a judicialização da política é um processo que se alimenta da pressão de interesses econômicos e sociais. Assim, esses grupos utilizam a possibilidade de veto do tribunal na realização de seus objetivos. Carvalho ressalta que, até junho de 2003, das 2.813 ADIns impetradas, um total de 740 (26,31\%) foram por entidades de classe ou confederações sindicais. ${ }^{26}$

Os partidos políticos por sua vez, até junho de 2003, ocupavam o terceiro lugar no rol dos impetrantes de ADIns s (20,97\%), só ficando atrás das confederações sindicais ou entidades de classe, e governadores de Estado. Werneck Vianna constatou que, de 1988 até 1998, 74\% das ADIns impetradas foram oriundas dos

${ }^{24}$ CARVALHO, Ernani Rodrigues. Em busca da judicialização da política no Brasil: apontamentos para uma nova abordagem. Revista de Sociologia Política, Curitiba, n. 23, p. 115-126, nov. 2004.

${ }^{25}$ Sobre o tema, ver o artigo de PAIXÃO, Cristiano; BARBOSA, Leonardo de Andrade. A memória do direito na ditadura militar: a cláusula de exclusão da apreciação judicial observada como um paradoxo. Revista do Instituto de Hermenêutica Jurídica, Porto Alegre, v. 1, n. 6, p. 57-78, 2008.

${ }^{26}$ CARVALHO, Ernani Rodrigues. Em busca da judicialização da política no Brasil: apontamentos para uma nova abordagem. Revista de Sociologia Política, Curitiba, n. 23, p. 115-126, nov. 2004. 
partidos de oposição. ${ }^{27}$ Igualmente, para Carvalho, o uso dos tribunais pela oposição ocorre como uma alternativa para barrar as alterações trazidas pela maioria, ou seja, esses partidos utilizam-se dos tribunais para inviabilizar as alterações em curso. ${ }^{28}$ Araújo e Magalhães também observam que o notável desenvolvimento do controle de constitucionalidade em países como a França e a Alemanha decorre da exploração dos tribunais constitucionais desses países por (fatores) políticos para fins político-partidários, com o objetivo de ganharem aquilo que normalmente perderiam por meio de processos legislativos normais. ${ }^{29}$

Nessa linha, a inefetividade das instituições majoritárias diz respeito à incapacidade dessas instituições em darem provimento às demandas sociais, que acabam encontrando dificuldade para serem efetivadas quando agregam alto custo ou não envolvam interesse suficiente. Para Castro, "a judicialização da política ocorre porque os tribunais são chamados a se pronunciar onde o funcionamento do Legislativo e do Executivo se mostra falho insuficiente ou insatisfatório." Por outro lado, em momentos de grave crise, como a ocorrida no Brasil, no final dos anos 80 e início da década de 90, o STF optou pela não-interferência, fenômeno que foi denominado por Antonio Araújo, segundo Carvalho, como "prudencialismo", isto é, adotou uma posição de cautela nos momentos iniciais da transição democrática, deixando que o regime democrático se consolidasse.

Dessa forma, constata-se que quase todas as condições estão presentes no caso brasileiro. Com efeito, a posição privilegiada que assumiu a jurisdição constitucional, redefinindo o significado cultural e de determinação do papel institucional do judiciário, a partir da Constituição de 1988, demonstra claramente a presença dessas condições no cenário político-jurídico brasileiro. Por outro lado, Souza

${ }^{27}$ VIANNA, Luiz Werneck et al. A judicialização da política e das relações sociais no Brasil. Rio de Janeiro: Revan, 1999.

${ }^{28}$ CARVALHO, Ernani Rodrigues. Em busca da judicialização da política no Brasil: apontamentos para uma nova abordagem. Revista de Sociologia Política, Curitiba, n. 23, p. 115-126, nov. 2004.

${ }^{29}$ ARAÚJO, A.; MAGALHÃES. P. C. A justiça constitucional: uma instituição contra as maiorias? Análise Social: revista do Instituto de Ciências Sociais da Universidade de Lisboa, Lisboa, v. 35, p. 207-247, 2000. Disponível em: <http://analisesocial.ics.ul.pt/docum entos/1218810451D6gVF8jb0Dg12PO1.pdf>. Acesso em: 6 nov. 2008. 
e Lamounier chamam a atenção para a liberdade dos juízes em paralisar políticas públicas, bem como a sua atuação crescente na arena política como uns dos males do fenômeno da "judicialização":

A liberdade de que desfrutam os juízes, até os de primeira instância, para tomar decisões diferentes em casos similares e o poder a eles concedido para paralisar políticas públicas vêm estimulando a sociedade a buscar no Judiciário a solução de seus conflitos sociais e políticos. O resultado tem sido os males gêmeos conhecidos no debate público como a "judicialização da política" e a "politização do Judiciário", males esses que sobrecarregam os tribunais e comprometem sua capacidade de ser imparciais. Em adição a isso, o alcance da verificação de constitucionalidade é tal que os tribunais são inevitavelmente dragados para a arena política. O Judiciário pode deliberar sobre a constitucionalidade não apenas de leis ordinárias aprovadas pelo Legislativo ou das medidas provisórias editadas pelo Executivo, mas até de emendas constitucionais, dado o seu poder de questionar qualquer um desses instrumentos em relação quer ao mérito quer ao método de deliberação pelo qual as decisões foram tomadas. ${ }^{30}$

Desse modo, a expansão do Poder Judiciário para a arena política, especificamente no caso da ADIn no 1.351, trouxe conseqüências diretas para o sistema político representativo e partidário, porquanto diz respeito à intervenção do Judiciário no processo de reforma política e, ainda, na determinação do modo operacional do sistema partidário. Seguindo a linha da lição de Tavares, parte-se da premissa de que os sistemas eleitoral e partidário são elementos que compõe o sistema real de governo, de tal modo que a sua funcionalidade dependerá da interação estratégica entre esses elementos juntamente com a cultura política e o ambiente sociopolítico sobre os quais opera. ${ }^{31}$

\footnotetext{
${ }^{30}$ SOUZA, Amaury de; LAMOUNIER, Bolívar. O futuro da democracia: cenários político-institucionais até 2022. Estudos Avançados, São Paulo, v. 20, n. 56, 2006. Disponível em: <http://www.scielo.br> Acesso em: 9 jul. 2008.

31 TAVARES, José Antônio Giusti. Reforma política e retrocesso democrático: agenda para reformas pontuais no sistema eleitoral e partidário brasileiro. Porto Alegre: Mercado Aberto, 1998 .
} 
Em razão disso, não se trata do fenômeno de judicialização da política procedente das incertezas trazidas pelo Estado Social, conforme apresentado por Vianna. ${ }^{32}$ Segundo o autor, a lei, originária do Poder Legislativo, precisaria ter seu significado completado pelo Poder Judiciário quando provocado pelas instituições e pela sociedade civil em decorrência das incertezas e efemeridades que acompanhavam o Estado Social, transformando o seu papel em "legislador implícito”. Já em relação ao caso em tela, os partidos de oposição, ou minoritários, utilizaram-se da litigância constitucional como uma arma contramajoritária, com o objetivo de barrar as alterações trazidas pela maioria.

Desse modo, a judicialização do processo político envolve aspectos institucionais que se remetem diretamente à governabilidade do Estado, isto é, a sua "capacidade de efetivar a política definida pelo Governo", cujo tema não é pacífico no Supremo, considerando o polêmico debate entre eficiência e democracia, o qual não será analisado no presente estudo. ${ }^{33}$

Ademais, as divergentes decisões nas ADIns n 1.354 e 1.351 , em que se julgaram a constitucionalidade e a inconstitucionalidade da cláusula de barreira, respectivamente, remetem ainda à derradeira questão desse estudo: o grau de influência de circunstâncias políticas externas nas decisões do Supremo. Com efeito, ambas as decisões foram coerentes com interesses governamentais ad hoc, isto é, relativas a necessidades políticas para se manter coesa a base de sustentação do governo em momentos determinados, conforme passaremos a analisar.

\section{A politização da justiça e as influências externas sobre a decisão do STF nas ADINS no 1.354 e 1.351}

Alguns autores, assim como Oliveira, entendem a politização da justiça como o evento em que o Judiciário é acionado para intervir no processo político.

\footnotetext{
${ }^{32}$ VIANNA, Luiz Werneck et al. A judicialização da política e das relações sociais no Brasil. Rio de Janeiro: Revan, 1999.

${ }^{33}$ FERREIRA FILHO, Manoel Gonçalves. Constituição e governabilidade: ensaio sobre a (in) governabilidade brasileira. São Paulo: Saraiva, 1995.
} 
No entanto, a abordagem que aqui se pretende não se restringe ao requerimento da tutela jurisdicional, mas volta-se ao estudo dos fatores políticos que passam a influenciar a forma como o Tribunal decide. ${ }^{34}$

Sabendo-se que a declaração de inconstitucionalidade do dispositivo da cláusula de barreira (art. 13 da Lei no 9.096/95), pela ADIn no 1.351-3, foi exatamente o oposto do julgamento proferido na ADIn no $1.354-8$, faz-se necessário o exame das questões políticas que estavam nos bastidores do julgamento de ambos os acórdãos. Deve-se lembrar que o Ministro Relator Marco Aurélio na ADIn n ${ }^{\circ}$ 1.351-3, havia acompanhado o voto do então Ministro Relator Maurício Corrêa no julgamento da ADIn $\mathrm{n}^{\circ}$ 1.354-8, no sentido de declarar a constitucionalidade da cláusula de barreira.

Além disso, a decisão do STF em manter o poder de barganha dos pequenos partidos para a aprovação de projetos governamentais não torna desnecessária a formação de uma maioria na Câmara dos Deputados, apesar do obstáculo que é o sistema eleitoral de lista aberta. Com efeito, tem-se buscado, no Congresso Nacional, outros meios para o restabelecimento da cláusula de barreira, com a finalidade de corrigir as distorções que foram mantidas pela decisão do STF na ADIn $n^{\circ} .1 .351$.

Nesse sentido, foi aprovada, em 27 de fevereiro de 2007, pela Comissão de Constituição e Justiça do Senado Federal, a proposta de mudança na Constituição que restaura a cláusula de barreira da seguinte forma: passa a ser permitida a distinção entre partidos pequenos e grandes, sendo que "grandes partidos" seriam considerados aqueles que recebessem, no mínimo, 5\% dos votos para a Câmara em pelo menos nove estados. Assim, os partidos pequenos não poderiam participar de comissões do Congresso e também não poderiam ser indicados para cargos de lideranças na Câmara e no Senado.

${ }^{34}$ OLIVEIRA, Vanessa Elias de. Judiciário e privatizações no Brasil: existe uma judicialização da política? DADOS: revista de Ciências Sociais, Rio de Janeiro, v. 48, n. 3, p. 559-587, 2005. Disponível em: <http://www.scielo.br/pdf/dados/v48n3/a04v48n3.pdf >. Acesso em: 13 jul. 2008. 
Dessa forma, a decisão do STF será analisada nesta seção a partir da perspectiva de sua suscetibilidade a pressões externas. Apesar da prerrogativa de guardião da Constituição Federal, o Supremo Tribunal Federal, assim como as demais cortes superiores, também está vulnerável a influências políticas. Nesse sentido avalia Plauto Faraco de Azevedo:

[...] a tentativa de influenciar o rumo das decisões judiciais é sensível nos tribunais superiores, nos quais os juízes são nomeados pelo chefe do Poder Executivo, com a ratificação do Senado Federal. As decisões dos tribunais superiores praticamente sempre importam à condução da política do Executivo, sendo muito humano sentir-se o magistrado grato a quem o nomeia, o que pode fazê-lo inclinar-se em favor da política que aquele deseja imprimir. ${ }^{35}$

Desse modo, a fim de confrontar as decisões do Supremo Tribunal Federal nos casos das ADIns 1.354 e 1.351 com o contexto político existente, será utilizado como metodologia no próximo subitem a análise dos seguintes cenários políticos: o anterior às eleições de 2002, o imediatamente posterior às eleições e, por fim, das modificações ocorridas no sistema partidário após seis meses de governo Lula.

\subsection{A influência das mudanças no cenário político do Congresso Nacional nas decisões do Supremo Tribunal Federal}

Fabiano Santos, com a intenção de observar a capacidade do Poder Executivo de intervir na agenda do Legislativo (presidencialismo de coalizão), faz uma análise científica do cenário anterior às eleições de 2002, do cenário imediatamente posterior às eleições e, por fim, das modificações ocorridas no sistema partidário após seis meses de governo Lula. A ideia central do autor parte do princípio de que:

[...] a governabilidade em nosso presidencialismo de coalizão é função da existência de um programa bem definido de políticas defendido pelos parceiros. A existência desse programa é função, por sua vez, da distância do

\footnotetext{
${ }^{35}$ AZEVEDO, Plauto Faraco de. Da politicidade do poder judiciário. Notícia do Direito Brasileiro, Brasília, n. 10, p. 49-60, jan. 2005. p. 57
} 
status quo em relação às políticas ideais dos partidos que compõem a coalizão. ${ }^{36}$

Nessa linha, no primeiro cenário, anterior às eleições de 2002, observou-se que a visão prevalecente entre os parlamentares do PSDB, PFL, PPB e PMDB tornou possível a aprovação da agenda de redução do setor público na economia e da reconfiguração da máquina administrativa do Estado. No entanto, com o passar do tempo, essa concordância diminuiu, gerando uma espécie de "paralisia decisória ou contexto de ingovernabilidade". ${ }^{37}$ As políticas aprovadas passam ser as do "varejo" e a manutenção da coalizão, instrumental. Diante disso, surge a necessidade de os partidos se diferenciarem, marcando posição junto ao eleitorado a fim de aumentar o seu capital político. Essa dinâmica marcou os últimos anos do governo FHC, sendo um dos seus reflexos o rompimento da aliança entre os partidos PSDB e PFL - pilar dos dois mandatos de Fernando Henrique na presidência - que foi uma das causas da vitória do PT nas eleições presidenciais de 2002.

No segundo cenário, imediatamente após as eleições de 2002, houve uma alteração significativa na correlação de forças no interior da Câmara dos Deputados. O PT obteve o maior crescimento na Câmara (33 cadeiras), ao passo que os dois principais partidos de sustentação ao governo FHC, PSDB e PFL sofreram as maiores derrotas, 28 e 21 cadeiras perdidas. Dos sete grandes partidos, o PDT sofre a menor perda (4 cadeiras). Dentre os pequenos partidos, o PL e PPS cresceram de maneira significativa em relação ao pleito de 1998. Nesse sentido, houve uma diminuição da força dos grandes partidos e um aumento no número efetivo

\footnotetext{
${ }^{36}$ SANTOS, Fabiano. Em defesa do presidencialismo de coalizão. In: SOARES, G. A. D.; RENNÓ, L. (Org.). Reforma política: lições da história recente. Rio de Janeiro: Fundação Getúlio Vargas, 2006. p. 285. Segundo Leão Viana, Santos vê, com isso, que o sistema multipartidário aliado com o sistema proporcional de lista aberta é o principal responsável pela prática de freios e contrapesos em nossa democracia, ou seja, nosso modelo de “presidencialismo de coalizão" é profundamente democrático. VIANA, João Paula Saraiva Leão. Reforma política: cláusula de barreira na Alemanha e no Brasil. Porto Velho: EDUFRO, 2006.

${ }^{37}$ SANTOS, Fabiano. Em defesa do presidencialismo de coalizão. In: SOARES, G. A. D.; RENNÓ, L. (Org.). Reforma política: lições da história recente. Rio de Janeiro: Fundação Getúlio Vargas, 2006. p. 286.
} 
de partidos, o que para Santos ${ }^{38}$ significa uma "expressão clara da diminuição do poder parlamentar de partidos como PSDB, PFL, PMDB e PPB, e da emergência de

novas forças, tais como PL, PSB, PCdoB e PPS”, formando um cenário de governo de minorias. Logo, o comportamento de partidos de centro, como o PSDB e o PMDB, seria decisivo para a governabilidade. Desse quadro, resultou uma mudança no modelo de presidencialismo de coalizão, ou seja, essa fragmentação na Câmara dos Deputados só seria superada se os partidos "estivessem dispostos a negociar com o governo em torno de conteúdos das políticas públicas propostas, e não mais em torno dos cargos e verbas a serem distribuídos, o que, por sua vez, pressuporia um Congresso fortalecido em suas prerrogativas decisórias." ${ }^{39}$

No terceiro cenário, o governo Lula seguiu a normalidade da política brasileira, ou seja, estimulou a troca de legendas de partidos originariamente de oposição em direção a partidos aliados e convidou o PMDB, partido de centro, para fazer parte da base governista. Em função disso, o governo Lula, que havia iniciado a sua administração controlando apenas $40 \%$ das cadeiras na Câmara dos Deputados, termina os primeiros seis meses com o apoio de $62 \%$ delas. Interessante observar que o PMDB foi um dos partidos membros da candidatura contra a qual Lula se abateu no segundo turno das eleições presidenciais, e que passa, após seis meses de governo, a fazer parte da coalizão de apoio ao novo presidente. Nesse sentido, Santos enfatiza que "Lula optou por reduzir os custos de transação no Legislativo, montando uma coalizão de ampla maioria, tornando a cooperação de partidos como o PSDB e o PFL desnecessária para a definição e aprovação da agenda governamental"40

${ }^{38}$ SANTOS, Fabiano. Em defesa do presidencialismo de coalizão. In: SOARES, G. A. D.; RENNÓ, L. (Org.). Reforma política: lições da história recente. Rio de Janeiro: Fundação Getúlio Vargas, 2006. p. 290.

${ }^{39}$ SANTOS, Fabiano. Em defesa do presidencialismo de coalizão. In: SOARES, G. A. D.; RENNÓ, L. (Org.). Reforma política: lições da história recente. Rio de Janeiro: Fundação Getúlio Vargas, 2006. p. 290.

${ }^{40}$ SANTOS, Fabiano. Em defesa do presidencialismo de coalizão. In: SOARES, G. A. D.; RENNÓ, L. (Org.). Reforma política: lições da história recente. Rio de Janeiro: Fundação Getúlio Vargas, 2006. p. 292. 
Observa-se, com isso, que a decisão do STF de derrubar a cláusula de barreira foi no sentido de evitar também a perda da base aliada do governo, o qual tinha se afastado dos partidos majoritários, mantendo a coalizão com pequenos partidos, com a exceção do PMDB. Ou seja, a decisão foi de acordo com o interesse governamental, já que a cláusula de barreira acabaria com a coalizão de partidos existente.

Por essa razão, ficou também demonstrada a pouca força do Congresso para fazer cumprir uma lei promulgada há mais de onze anos quando da decisão do STF que declarou a inconstitucionalidade da cláusula de barreira. Dito de outro modo, pequenos partidos, mesmo que não tivessem cumprido a regra de transição, conseguiram obter cargos de lideranças como foi a caso da ocupação da presidência da Câmara e de outras comissões por pequenos partidos como o PC do B.

\section{Considerações finais}

Desde 1945, o Brasil mantém o sistema proporcional de representação associado ao regime presidencialista de governo, cuja interação tem resultado em diversos obstáculos para o processo decisório. Dentre os principais, está o excessivo liberalismo para a formação de partidos políticos após o período de ditadura militar (1964-1985), que foi um fator determinante para o assentamento das características da nova ordem política. Com efeito, o sistema partidário brasileiro atual demonstra ser pouco institucionalizado com base em três critérios fundamentais: falta de estabilidade nos padrões de competição entre os partidos políticos; inexistência de raízes partidárias mais profundas na sociedade; e, por último, os partidos e eleições no Brasil não apresentam legitimidade pública, isto é, falta nesses institutos credibilidade perante o público.

Nesse sentido, a criação da cláusula de barreira, institucionalizada pela Lei no 9.096/95, foi com o intuito de corrigir distorções no sistema democrático representativo, eis que a existência de pequenas bancadas no Congresso representa um obstáculo à formação de maiorias sólidas para a votação de questões relevantes. Por outro lado, a interpretação do Supremo Tribunal Federal, na ADIn n 1.351 , 
foi de que a cláusula de barreira tornar-se-ia mais uma limitação ao funcionamento da agremiação partidária, juntamente com os quocientes eleitoral e partidário que integram o sistema proporcional, conforme destacou o Ministro Gilmar Mendes em seu voto, provocando, assim, um "sacrifício radical das minorias. ${ }^{41}$

Contudo, as insurgências contra a cláusula de barreira foram alijadas em virtude do julgamento, em sede de liminar, da ADIn no 1.354-8 que, por unanimidade, reconheceu a sua constitucionalidade. Alegou-se que o referido artigo 13 não viola $o$ princípio da igualdade, pois os partidos concorrem em igualdade de condições, ressalvada a participação no fundo partidário e o "direito de antena”, ou horário gratuito de rádio e televisão, para aqueles que não preencherem as condições do dispositivo.

Sob o prisma do processo de judicialização da política, observou-se que o Supremo Tribunal Federal não foi acionado com o objetivo de salvaguardar a Constituição Federal, mas usado pela oposição partidária como uma alternativa para inviabilizar as alterações em curso no que concerne à reforma política, isto é, para os partidos menores ganharem aquilo que normalmente perderiam por meio de processos legislativos normais. Além disso, a judicialização do processo político, no caso em tela, envolve aspectos institucionais que se remetem diretamente à governabilidade do Estado, isto é, a sua capacidade de efetivar a política definida pelo Governo, cuja apreciação não é tema pacífico no Supremo, tendo em vista o controverso debate entre eficiência e democracia.

Desse modo, sob o enfoque do evento denominado como politização da justiça, em razão das divergentes decisões proferidas nas ADIns n $n^{\circ} 1.354$ e 1.351, analisaram-se os cenários políticos no período anterior às eleições de 2002, o imediatamente posterior às eleições e, por fim, as modificações ocorridas no sistema partidário após seis meses de governo Lula. Assim, observou-se que, no primeiro cenário, a base governista era formada por partidos majoritários tais como PSDB, PFL, PPB e PMDB, que superariam a barreira de 5\%. No segundo cenário, o PT

${ }^{41}$ BRASIL. Supremo Tribunal Federal. Ação direta de inconstitucionalidade. Partido Comunista do Brasil e Congresso Nacional. ADIn $n^{\circ}$ 1.351-3. Tribunal Pleno. Relator: Ministro Marco Aurélio. Brasília, 30 de março de 2007. Disponível em: <http://www.stf.jus.br/ imprensa/pdf/votoerosadi1351.pdf>. Acesso em: 9 jul. 2008. 
obteve o maior crescimento na Câmara dos Deputados, ao passo que os dois principais partidos de sustentação ao governo Fernando Henrique Cardoso, PSDB e PFL, sofreram as maiores derrotas. Pequenos partidos como o PL e PPS cresceram de maneira significativa, o que resultou na diminuição da força dos grandes partidos e um aumento no número efetivo de partidos. No terceiro e último cenário, o governo Lula estimulou a troca de legendas de partidos originariamente de oposição em direção a partidos aliados e convidou o PMDB, partido de centro, para fazer parte da base governista. Em função disso, o governo Lula, que havia iniciado a sua administração controlando apenas $40 \%$ das cadeiras na Câmara dos Deputados, termina os primeiros seis meses com o apoio de $62 \%$ delas. Essa estratégia tornou a cooperação de partidos como o PSDB e PFL desnecessária para a definição e aprovação da agenda governamental.

Portanto, caso a cláusula de barreira tivesse sido mantida pelo Supremo, a base de sustentação ao governo Lula na Câmara dos Deputados não subsistiria. Além do que, o próprio presidente da Câmara dos Deputados, Aldo Rebelo (PC do B - SP), no período de 2005 a 2007, perderia o mandato. Também aumentaria a força dos partidos, agora de oposição, como PSDB e PFL, dificultando a aprovação da agenda presidencial.

Por fim, conclui-se que as decisões do Supremo Tribunal Federal em períodos distintos, 1996 e 2006, foram ad hoc, ou seja, de acordo com as necessidades políticas do governo para manter e /ou aumentar a sua base governista em situações específicas. Sendo assim, as decisões foram instrumentais, não obstante os argumentos fundamentados em princípios apresentados pelo Plenário.

\section{The judicialization of the political process and the politicization of justice: an analysis of the supremo tribunal federal intervention in the party political process}

\section{Abstract}

The main focus of this study is to analyze the control of constitutionality of the Supremo Tribunal Federal in regard to the partisan political process, starting 
from the analysis of the ADIns (Direct Act of Unconstitutionality) n. 1.354, brought into court by the Partido Social Cristão - PSC, and the main action, n 1.351, demanded by the Partido Democrático Trabalhista - PDT e pelo Partido Comunista do Brasil - PC do B, aiming to hinder the validity of the clause of barrier, foreseen in article 13 of the Federal Law n. 9.096/95 - Law of the Political Parties. Both judgments had unanimous votings, although divergent decisions. Thus, in the judgment of the ADIn $n^{\circ} 1.354$, judged in 1996, it was rejected the declaration of unconstitutionality of the barrier clause. However, in December of 2006, the judgment of the main action, ADIn $n^{\circ} 1.351$, its granting was judged. In such a way, in order to evaluate the legal and politics implications of these decisions for the Brazilian democracy, two effect are investigated: the judicialization of the political process and the politicization of justice. The first one, basically, is characterized by the intervention of Supreme the political dispute from the judgment of the ADIn $\mathrm{n}^{\circ} 1.351-3$, and the second one by the political factors that influenced the way as the Supremo Tribunal Federal decided and, for evidence, the cause of its divergent judgments, in the ADIn $n^{\circ} 1.354$ and 1.351. Finally, through this panorama, it is inquired the political impact of the STF in the definition of the rules of the democratic system, not only as the "guard of the Federal Constitution", which implies a certain neutrality in its decisions, but also by the influence of convenient political matters, decurrent of the composition of the federal government and the National Congress. At last, it is concluded that both decisions of the Supremo, on distinct periods, 1996 and 2006, were instrumental, which means that they were taken according to the government political necessities to maintain or/and increase its governmental basis in specific situations.

Keywords: Constitutionality control. Judicialization of the politics. Politicization of justice. Political parties. Clause of barrier.

\section{Referências}

ARAÚJO, A.; MAGALHÃES, P. C. A justiça constitucional: uma instituição contra as maiorias? Análise Social: Revista do Instituto de Ciências Sociais da Universidade de Lisboa, Lisboa, v. 35, p. 207-247, 2000. Disponível em: <http://analisesocial.ics. ul.pt/documentos/1218810451D6gVF8jb0Dg12PO1.pdf>. Acesso em: 6 nov. 2008. 
AZEVEDO, Plauto Faraco de. Da politicidade do poder judiciário. Notícia do Direito Brasileiro, Brasília, n. 10, p. 49-60, jan. 2005.

BISCHOFF, Álvaro Walmrath; AXT, Gunter; SEELIG, Ricardo Vaz. Histórias de vida do Ministério Público do Rio Grande do Sul: a Constituinte de 1988. Porto Alegre: Procuradoria-Geral de Justiça, Memorial do Ministério Público, 2006.

BRASIL. Supremo Tribunal Federal. Ação Direta de Inconstitucionalidade. Partido Social Cristão e Congresso Nacional. ADIn $n^{\circ}$ 1.354-8. Tribunal Pleno. Relator: Ministro: Maurício Corrêa. Brasília, 7 de fevereiro de 1996. Disponível em: $<$ http:// www.stf.jus.br/arquivo/cms/publicacaoRTJ/anexo/206_1.pdf>. Acesso em: 9 jul. 2008.

BRASIL. Supremo Tribunal Federal. Ação direta de inconstitucionalidade. Partido Comunista do Brasil e Congresso Nacional. ADIn $n^{\circ}$ 1.351-3. Tribunal Pleno. Relator: Ministro Marco Aurélio. Brasília, 30 de março de 2007. Disponível em: $<$ http://www.stf.jus.br/imprensa/pdf/votoerosadi1351.pdf $>$. Acesso em: 9 jul. 2008.

CAPPELLETTI, Mauro. Juizes legisladores? Porto Alegre: S. A.Fabris, 1999.

CAPPELLETTI, Mauro. O controle de constitucionalidade das leis no direito comparado. Porto Alegre: S. A. Fabris, 1984.

CARVALHO, Ernani Rodrigues. Em busca da judicialização da política no Brasil: apontamentos para uma nova abordagem. Revista de Sociologia Política, Curitiba, n. 23, p. 115-126, nov. 2004.

CASTRO, Marcos Faro de. O Supremo Tribunal Federal e a judicialização da política. São Paulo, 2009. Disponível em: <http://www.anpocs.org.br/portal/publicacoes/ rbcs_00_34/rbcs34_09.htm> Acesso em: 28 ago. 2010.

CITTADINO, Gisele. Judicialização da política, constitucionalismo democrático e separação de poderes. In: WERNECK VIANNA, Luiz (Org.). A democracia e os três poderes no Brasil. Belo Horizonte: UFMG, Rio de Janeiro: IUPERJ/FAPERJ, 2002. p. 17-42.

CITTADINO, Gisele. Pluralismo, direito e justiça distributiva: elementos da filosofia constitucional contemporânea. 3 ed. Rio de Janeiro: Lumen Júris, 2004. 
CRUZ, Álvaro Ricardo de Souza. Breve histórico do Supremo Tribunal Federal e do controle de constitucionalidade brasileiro. In: SAMPAIO, José Adércio Leite. Crise e desafios da Constituição. Belo Horizonte: Del Rey, 2003. p. 201-254.

FERREIRA FILHO, Manoel Gonçalves. Constituição e governabilidade: ensaio sobre a (in)governabilidade brasileira. São Paulo: Saraiva, 1995.

HABERLE, Peter. Hermenêutica constitucional: a sociedade aberta dos intérpretes da Constituição: contribuição para a interpretação pluralista e "procedimental" da Constituição. Tradução Gilmar Ferreira Mendes. Porto Alegre: S. A. Fabris, 1997.

MACHADO, Sérgio. Reforma político-partidária. Brasília: Senado Federal, 1998. Relatório Final.

MAINWARING, Scott P. Sistemas partidários em novas democracias: o caso do Brasil. Tradução Vera Pereira. Porto Alegre: Mercado Aberto, 2001.

MENDES, Gilmar Ferreira. Jurisdição Constitucional: o controle abstrato de normas no Brasil e na Alemanha. 3. ed. São Paulo: Saraiva, 1999.

OLIVEIRA, Vanessa Elias de. Judiciário e privatizações no Brasil: existe uma judicialização da política? DADOS: revista de Ciências Sociais, Rio de Janeiro, v. 48, n. 3, p. 559-587, 2005. Disponível em: <http://www.scielo.br/pdf/dados/v48n3/ a04v48n3.pdf>. Acesso em: 13 jul. 2008.

SANTOS, Fabiano. Em defesa do presidencialismo de coalizão. In: SOARES, G. A. D.; RENNÓ, L. (Org.). Reforma política: lições da história recente. Rio de Janeiro: Fundação Getúlio Vargas, 2006. p. 281-295.

SANTOS, Marcelo Paiva dos. A história não contada do Supremo Tribunal Federal. Porto Alegre: S. A. Fabris, 2009.

SOUZA, Amaury de; LAMOUNIER, Bolívar. O futuro da democracia: cenários político-institucionais até 2022. Estudos Avançados, São Paulo, v. 20, n. 56, 2006. Disponível em: < http://www.scielo.br > . Acesso em: 9 jul. 2008.

TAVARES FILHO, Newton. Democratização do processo de nomeação dos ministros do Supremo Tribunal Federal. Brasília: Consultoria Legislativa da Câmara dos Deputados, 2006. Disponível em: <http://apache.camara.gov.br/portal/arquivos/ Camara/internet/publicacoes/estnottec/tema6/2006_469.pdf.>. Acesso em: 21 out. 2008. 
TAVARES, José Antônio Giusti. Reforma política e retrocesso democrático: agenda para reformas pontuais no sistema eleitoral e partidário brasileiro. Porto Alegre: Mercado Aberto, 1998.

VIANA, João Paula Saraiva Leão. Reforma política: cláusula de barreira na Alemanha e no Brasil. Porto Velho: EDUFRO, 2006.

VIANNA, Luiz Werneck et al. A judicialização da política e das relações sociais no Brasil. Rio de Janeiro: Revan, 1999. 


\section{Para publicar na revista Brasileira de Políticas Públicas, acesse 0 endereço eletrônico www.publicacoesacademicas.uniceub.br. Observe as normas de publicação, para facilitar e agilizar o trabalho de edição.}

